\title{
Response of lean premixed swirl tubular flame to acoustic perturbations
}

\author{
by
}

Kang MA ${ }^{1}$, Xiao YU ${ }^{1}$, Xiaoyao ZHAO ${ }^{1,2}$, Xinyan $\mathrm{LI}^{1}$, Shuiqing $\mathrm{LI}^{3}$, Dan $\mathrm{ZHAO}^{4}$, Baolu $\mathrm{SHI}^{{ }^{*}}$,

${ }^{1}$ School of Aerospace Engineering, Beijing Institute of Technology No.5 ZhongGuanCun South Street, Haidian, Beijing, 100081, CHINA

${ }^{2}$ Collaboration Innovation Institute of Civil-Military Integration, North University of China, Taiyuan, CHINA

${ }^{3}$ Department of Thermal Engineering, Tsinghua University, Beijing 100084, CHINA

${ }^{4}$ Department of Mechanical Engineering, College of Engineering, University of Canterbury, Private Bag 4800, Christchurch 8140, New Zealand

*Corresponding: Baolu SHI_E-mail: shibaolu@bit.edu.cn, smashingsky@hotmail.com Address: No.5 ZhongGuanCun South Street, Haidian, Beijing, 100081, CHINA Tel: +86-10-6891-3623

Fax: +86-10-6891-3623 


\begin{abstract}
This study experimentally examined the response of a lean premixed methane/air swirl tubular flame to the longitudinal acoustic perturbations. Experiments were conducted by varying the acoustic frequency $\left(f_{0}\right)$, acoustic power $\left(P_{0}\right)$ and inlet air flow rate $\left(Q_{\mathrm{A}}\right)$ to systematically study the acoustic-excited flame dynamics, including the flame stability, flame structure, heat release rate and acoustic pressure fluctuations. The results demonstrated that the lean tubular flame was much sensitive to longitudinal perturbations below $210 \mathrm{~Hz}$. Even at low power of $P_{0}$, the flame was forced to oscillate intensively when the perturbation was operated in two discontinuous frequency ranges of $f_{0}=150-200$ and $f_{0}=50-100 \mathrm{~Hz}$, while a weakened oscillation regime was observed in the middle range of $f_{0}=100-150 \mathrm{~Hz}$; a lower frequency (less than $50 \mathrm{~Hz}$ ) would extinguish the flame. An increase in $P_{0}$ intensified the flame oscillation under the perturbations of $50-100 \mathrm{~Hz}$, and even resulted in flame lift-off and blow off with $f_{0}$ between 150 and $200 \mathrm{~Hz}$. In comparison to $f_{0}$ and $P_{0}$, the effects of air flow rate $\left(Q_{\mathrm{A}}\right)$ seemed to be weaker. The proper orthogonal decomposition (POD) analysis was performed to interpret the contributions from the mean mode and fluctuating axial and circumferential modes that led to combustion instability. It was found that as the energy fraction of the axial mode exceeded 5.0\%, the flame lift-off appeared in the lean swirl tubular configuration.
\end{abstract}

Keywords: swirl tubular flame; lean premixed combustion; combustion instability; acoustic perturbation; proper orthogonal decomposition 


\section{Introduction}

By tangentially injecting the combustible mixture into a cylindrical combustor, a laminar tubular flame can be established in a swirling flow field [1]. Different from the general swirling turbulent flame, the swirl tubular flame is a deterministic laminar flame with flame diameter and length predictable for a given flow rate and mixture property [2]. It owns excellent thermal stability through forming uniformly distributed high-temperature burned gas inside the flame front; while the flame front is covered by the low-temperature unburned gas along the cylindrical burner wall. Hence the configuration enables long-time operation in practical application considering the low risk of burner ablation. Steady flames have been established within a wide equivalence ratio range from lean to rich with the mean tangential injection velocity varying from 10 to even $200 \mathrm{~m} / \mathrm{s}$ [3]. Considering its remarkable merits, over the past decades, the swirl tubular flame has been experimentally $[1,4,5]$ and theoretically [6-8] studied. A model for tangential injection has also been developed to examine the tubular flame characteristics [9]. A variety of configurations from micro-combustor to large size (12 inch) tubular flame burner [10] have been developed to meet industrial demands, including power generation [11-13], emissions reduction [14,15], flame stabilization [4] and flame synthesis [16].

Though it owns excellent aerodynamic and thermal stabilities, the swirl tubular flame also encounters combustion instability under certain conditions. In the premixed propane/air combustion under large flow rates (over $600 \mathrm{~m}^{3} / \mathrm{h}$ ) [5], high frequency oscillations were observed, which were identified as the tangential/radial mode acoustic resonant oscillations. In the hydrogen/air combustion [17] as well as lean oxy-fuel combustion of methane [3,18] and propane [19] under high oxygen concentrations (above 0.6), the observed high frequency oscillations were recognized as the axial mode acoustic resonant oscillations. Such instability phenomena severely limit the application of tubular flame to the aforementioned emission reduction, power generation, and flame synthesis. However, so far only very limited work has been reported. Near extinction, in the premixed and non-premixed tubular flame without rotation, the instability mechanisms were 
examined for the $\mathrm{H}_{2}, \mathrm{CH}_{4}$ and $\mathrm{C}_{3} \mathrm{H}_{8}$ mixtures [20,21], in which the inhibitory action of pure curvature on the onset of flame instability has been addressed. To meet the increasing demand of widening the practical application of swirl tubular flame, especially the full utilization of a steady and deterministic tubular flame at the extreme lean condition to yield ultralow pollutant emissions, it is indispensable to identify the flame dynamics under forced perturbations, such as acoustics and external electric fields [22], etc.

By introducing external acoustics, plenty of studies have been conducted to examine the combustion instability in a variety of combustion systems. In the swirling turbulent flame produced by a vane swirler, Palies et al. $[23,24]$ investigated the flame characteristics and proposed the flame transfer function (FTF) to describe the linear combustion instability and the flame description function (FDF) for non-linear behavior. In addition, the thermoacoustic oscillations associated with transverse acoustic modes were also systematically examined $[25,26]$. Under harmonic forcing of upstream mixture velocity, the bluff body stabilized turbulent premixed flames were reported to blow off over a range of forcing frequency between 50 and $400 \mathrm{~Hz}[27,28]$, and the mechanism for blow off has been elucidated by employing advanced laser techniques [29]. In the premixed flame stabilized on a heat-conducting bluff-body [30], with employing a fixed longitudinal forcing frequency of $100 \mathrm{~Hz}$ in inlet velocity, it was reported that heat exchange between bluff-body and surrounding reacting flow plays a crucial impact on the dynamic response. In lifted non-premixed jet flames [31], high magnitude and middle frequencies $(\sim 200 \mathrm{~Hz})$ acoustics were employed to successfully change the combustion regime and prevent the flame reattachment. These studies improved the understanding of flame dynamics under various conditions, and provided a valuable reference for the fundamental study of swirl tubular flame dynamics under perturbations.

Different from the flames aforementioned, without a swirler vane or bluff-body at the combustor center, the unique tubular flame is stabilized by swirl induced via tangential jet flow and laminarized through reaction in the swirling flow field, i.e., flame laminarization $[1,2,10]$. It is a deterministic laminar flame experiencing curvatures and stretches along either direction 
independently $[1,32]$. Therefore, the flame may be susceptible to external perturbations, especially in the direction perpendicular to the tangential jets, i.e., longitudinal excitations. Such a response is of significant interest to predict the flame stability at extreme conditions, such as ultra-lean burning, or pure oxygen combustion with ultrahigh heat release rate $[18,19]$. Hence, by axially introducing acoustic perturbations, this study experimentally investigated the characteristics of methane/air premixed tubular flame at the equivalence ratio $(\Phi)$ of 0.65 . The experiments were performed by varying the frequency $\left(f_{0}\right)$ and power $\left(P_{0}\right)$ of the acoustics, as well as the air flow rate $\left(Q_{\mathrm{A}}\right)$ or heat output $(P)$. The flame structure, flame stability, flow filed, heat release rate and acoustic pressure fluctuations have been investigated to examine the flame responses. And the proper orthogonal decomposition (POD) analysis was carried out to interpret the flame lift-off behaviors.

\section{Experimental apparatus}

Figure 1 shows a schematic of the experimental setup including the burner, loudspeaker and diagnostics. The burner is made of stainless steel with an inner diameter $(D)$ of $24 \mathrm{~mm}$ and it has four tangential slits to induce the combustible pre-mixture (A-A section). For each slit, the width is 2.5 $\mathrm{mm}$, and the length is $12 \mathrm{~mm}$. Accordingly, the geometry swirl number is calculated as 3.38 based on $S_{\mathrm{w}}=\pi^{*} D^{2} / 4 A_{\mathrm{t}}[1,10,33]$, where $A_{\mathrm{t}}$ is the total section area of the tangential slits. A quartz tube with inner diameter of $24 \mathrm{~mm}$ and length of $150 \mathrm{~mm}$ is connected to the open-end of the burner to permit flame photographing, heat release rate and flow velocity measurements. A coordinate is defined on the burner axis with its origin position parallel to the end of the tangential inlet. 


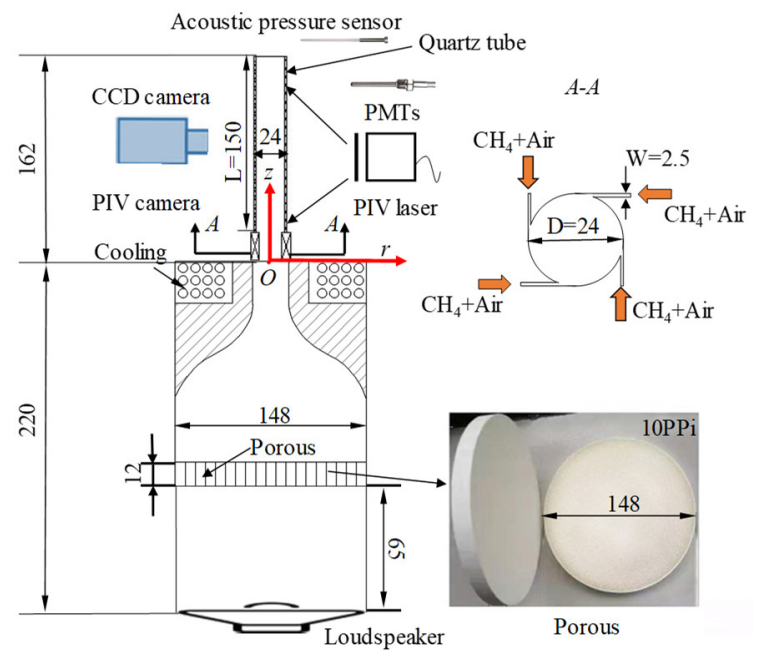

Fig. 1 Schematics of the experimental system.

The combustor is then mounted above an acoustics generator with $220 \mathrm{~mm}$ in length. Acoustic perturbations longitudinally propagate through a convergent nozzle cooled by water. In order to reduce the fluctuation level of the internal flow and obtain a uniform axial velocity distribution upstream of the swirl burner, a porous ceramic media with 10 PPi (Pores Per inch) is adopted to yield homogeneous acoustic perturbations prior to the combustor. The thickness and diameter of the media are 12 and $148 \mathrm{~mm}$, respectively. Fixed $65 \mathrm{~mm}$ upstream of the porous media, the loudspeaker ( $4 \Omega$, $20 \mathrm{~Hz} \sim 20 \mathrm{MHz}$ ) is excited by a sinusoidal signal (JUNTEK JDS-2900). The signal is amplified by an audio power amplifier (SAST SA-9006) before being input to the speaker. The magnitude of the acoustic wave is adjusted by varying the power of the amplifier $\left(P_{0}\right)$. In this work, the forcing power $\left(0<P_{0} \leq 20 \mathrm{~W}\right)$ and frequency $\left(f_{0}>20 \mathrm{~Hz}\right)$ were varied independently to demonstrate the dependence of flame response on the magnitude and frequency. By sweeping the forcing frequency and finding the maximum acoustic resonance under the cold flow condition $\left(Q_{\mathrm{A}}=35 \mathrm{~L} / \mathrm{min}, P_{0}=10\right.$ W), the eigenmode frequency of the entire setup was identified as $130 \mathrm{~Hz}$ [34].

The high-purity methane and dry air supplied by cylinders were well-premixed and then injected into the combustor through the tangential slits. The flow rates were determined by the volumetric flow rate controllers (D07-9E), which were provided by Beijing Seven-star Flow Company with the uncertainty of $\pm 2.5 \%$ [35] in the range of $0-100 \mathrm{~L} / \mathrm{min}$. 
A high-speed video camera (Phantom v7.3) integrated with F-S NIKKOR 50 MM F/1.4 lens was used to capture the flame structure confined in the quartz tube, with the frame rate of $1000 \mathrm{fps}$, resolution of $800 \times 600$ pixels, aperture of 2.8 and the exposure time of $0.001 \mathrm{~s}$. An acoustic pressure sensor (BSWA mpa416) was fixed at a radial distance of $10 \mathrm{~mm}$ away from the exit of the quartz tube, and the acoustic pressure data was collected by the capture card (cdaq-9171) together with the LabVIEW software.

To visualize the flow field, a high-speed particle image velocimetry (PIV) system (see Fig.S1 in the supporting information) was employed. The PIV system consists of a high-speed camera (Phantom v311) with a frame rate of 10000 fps, a continuous laser (MGL-W-532nm-18W) and a host computer. The laser emits a fan-shaped area with a thickness of $1 \mathrm{~mm}$ and $180 \mathrm{~mm}$ effective height of the photographing area. $\mathrm{TiO}_{2}$ particles with diameters of $0.5 \mu \mathrm{m}$ were seeded into air flow in the PIV measurements. The heat release rate fluctuations were characterized by the variation of $\mathrm{OH}^{*}$ chemiluminescence in the premixed flame, which was detected by a photomultiplier tube (PMT, 71D101-CR131) with a sample rate of $10000 \mathrm{~Hz}$.

\section{Results}

\subsection{Effects of acoustic frequency $f_{0}$}

At first, the stability of the swirl tubular flame without acoustic perturbation was examined, as presented in Fig. 2. In the tests, $Q_{\text {A }}$ was increased from 25 to $50 \mathrm{~L} / \mathrm{min}$, yielding a mean tangential injection velocity up to $7.42 \mathrm{~m} / \mathrm{s}$. A steady laminar flame was established between $\Phi=0.6$ and 1.15 regardless of $Q_{\text {A. As }} \Phi$ further increased, the flame was lifted off and eventually blew out at $\Phi \approx$ 1.35. The steady tubular flame range is a bit narrower, compared with our previous studies $(\Phi=0.5$ - 1.6) [1,15] which used a similar swirl tubular burner without acoustic generator. The hollow structure of the bottom geometry and cooling system may cause additional heat loss, resulting in extinction at the extreme lean or rich conditions. 


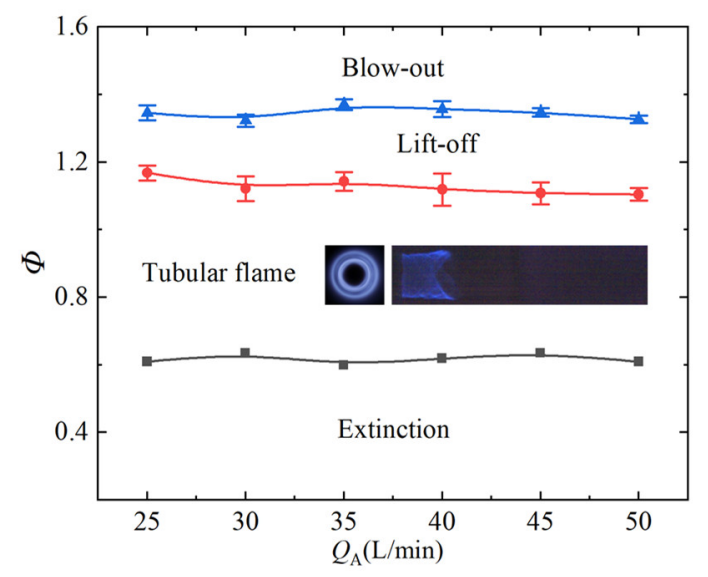

Fig. 2 Combustion regime diagram in the premixed $\mathrm{CH}_{4}$-air swirl tubular flame with no acoustic perturbation.

Then, a lean pre-mixture of $\Phi=0.65$ was selected to investigate flame responses to the acoustic perturbations. The value of $Q_{\mathrm{A}}$ was increased from 25 to $50 \mathrm{~L} / \mathrm{min}$ yielding a theoretical heat output of up to $1.88 \mathrm{~kW}$. Firstly, the acoustic power was fixed at $P_{0}=10 \mathrm{~W}$ while the perturbing frequency $f_{0}$ was varied. Figure 3 illustrates the combustion regime diagram that was mainly determined by the variation of flame structure and verified by the $\mathrm{OH}^{*}$ chemiluminescence recorded by PMT. The detailed variations of flame structure to $f_{0}$ have been recorded, and the corresponding instantaneous flame images are presented in Fig. 4 under the conditions of $Q_{\mathrm{A}}=35$ $\mathrm{L} / \mathrm{min}$ and $P_{0}=10 \mathrm{~W}$. Without acoustics, the swirl tubular flame is a quiescent laminar flame with Reynold number around 2,000.

Starting with a moderate frequency of $250 \mathrm{~Hz}, f_{0}$ was raised to even a few thousands $\mathrm{Hz}$, however, the anchored flame with tubular shape presented noisy (ultra-weak) oscillation; then the perturbing frequency was gradually and carefully decreased from $f_{0}=250 \mathrm{~Hz}$. As $f_{0}$ approaching to $200 \mathrm{~Hz}$, the anchored flame started to lift off $(\mathbf{m})$, oscillating inside the confined tube. As $f_{0}$ was further decreased, the flame continuously lifted off and eventually approached the tube exit around $f_{0}=170 \mathrm{~Hz}$. Thereafter the flame blew off $(\bullet)$.

Then the pre-mixture was ignited again around $f_{0}=100 \mathrm{~Hz}$, where the anchored flame exhibited weakened oscillations. As $f_{0}$ gradually decreased, intense flame oscillations appeared until flame extinction around $50 \mathrm{~Hz}$. In addition, when $f_{0}$ was raised from $100 \mathrm{~Hz}$, the flame started 
to blow off again around $f_{0}=150 \mathrm{~Hz}(\mathbf{\Delta})$. Concerning the effect of the air flow rate $\left(Q_{\mathrm{A}}\right)$, when $Q_{\mathrm{A}}$ was increased from 25 to $50 \mathrm{~L} / \mathrm{min}$, the critical $f_{0}$ that dominated the transition from weak oscillation to intense oscillation $(\nabla)$ gradually decreased. While the critical $f_{0}$ for flame quenching $(\diamond)$ was maintained around $50 \mathrm{~Hz}$, resulting in the shrinking of the intense oscillation region and broadening of the weakened oscillation region.

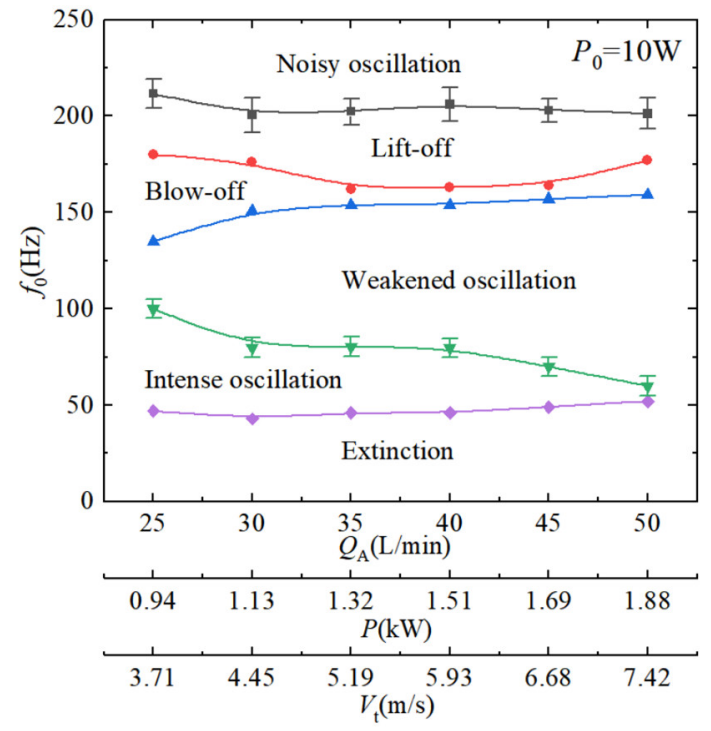

Fig. 3 Combustion regime diagram for the lean premixed swirl tubular flame perturbed by different acoustic frequencies $\left(P_{0}=10 \mathrm{~W}, \Phi=0.65\right)$.

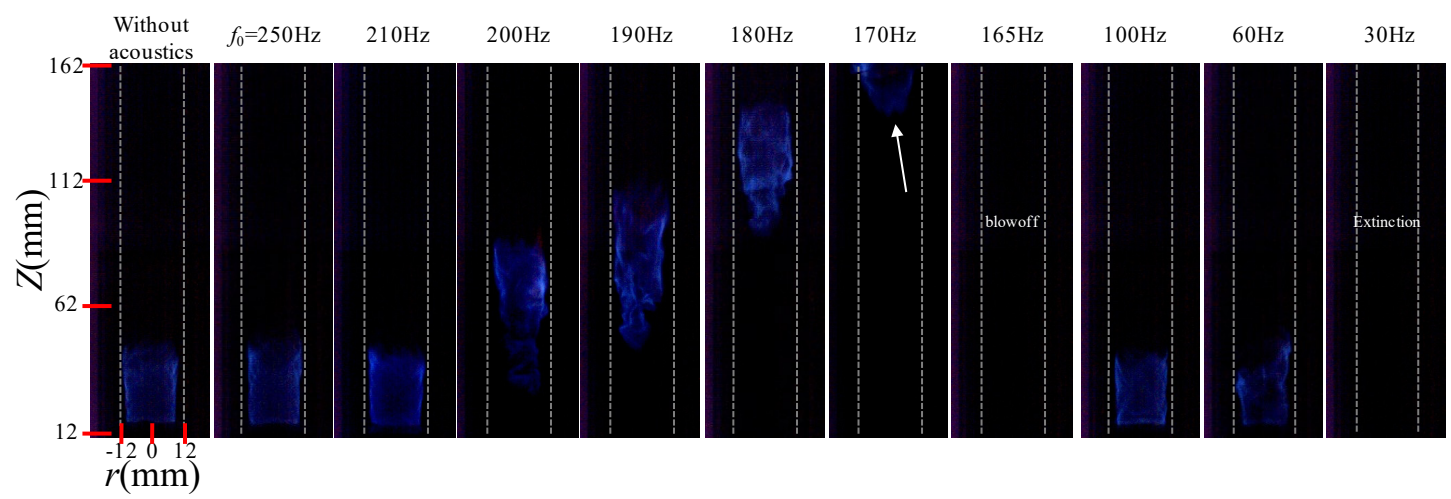

Fig. 4 Instantaneous $\mathrm{CH}_{4}$-air premixed flame images indicating flame responses to $f_{0}\left(Q_{\mathrm{A}}=35\right.$ $\left.\mathrm{L} / \min , P_{0}=10 \mathrm{~W}, \Phi=0.65\right)$.

The temporal variations of the tubular flame in oscillatory mode are shown in Fig. 5. Several typical perturbing frequencies were selected to illustrate the flame dynamics at different flame regimes. At $f_{0}=180 \mathrm{~Hz}$, the flame was lifted off, wrinkling and oscillating in the downstream. 
Under $f_{0}=100$ and $60 \mathrm{~Hz}$, the flame was anchored, maintaining almost tubular shape. The flame presented weak oscillations at $f_{0}=100 \mathrm{~Hz}$, while it oscillated inside the confined tube significantly at $f_{0}=60 \mathrm{~Hz}$.

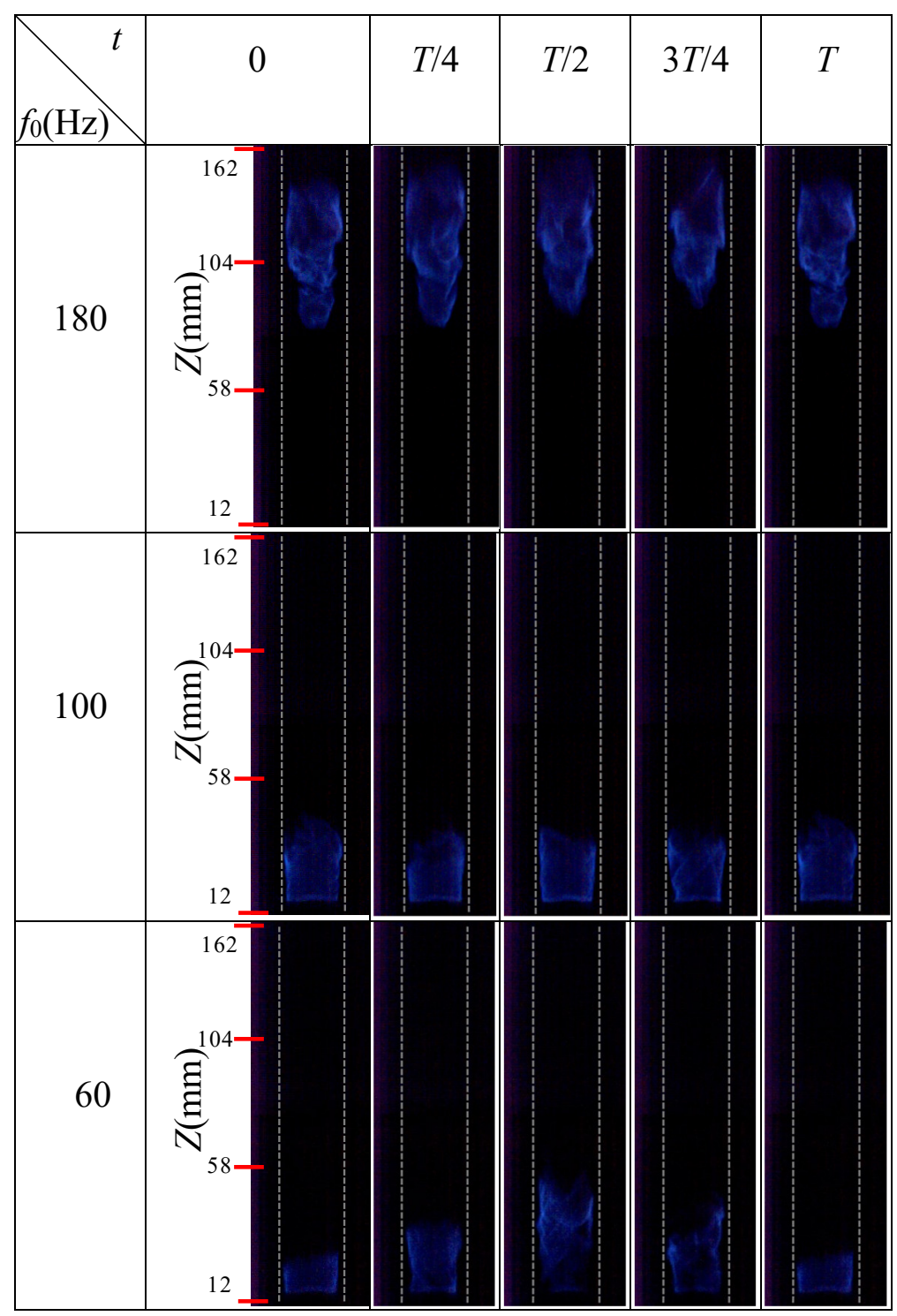

Fig. 5 Temporal variations of $\mathrm{CH}_{4}$-air premixed flame in a perturbation cycle $(T)$ under different perturbation frequencies $\left(Q_{\mathrm{A}}=35 \mathrm{~L} / \mathrm{min}, P_{0}=10 \mathrm{~W}, \Phi=0.65\right)$.

By simply calculating the temporal variation of the relative flame surface area ( $\tau=\Delta A /(\Delta \mathrm{t} \times A)$ $A$ : flame surface area, $\Delta \mathrm{t}$ : interval), the flame stretch rate in a perturbation cycle can be roughly estimated for the two cases of $f_{0}=100$ and $60 \mathrm{~Hz}$. The flame surface area ( $\bullet$ ) was calculated based on the flame images taken by the high-speed camera, following the procedure adopted in literature 
[36]. Figure 6 shows that the reduction of $f_{0}$, i.e., from $100 \mathrm{~Hz}$ (Fig. 6(b)) to $60 \mathrm{~Hz}$ (Fig. 6(a)), will increase the maximum stretch rate $(\nabla)$. The estimated maximum stretch rate reaches $390 \mathrm{~s}^{-1}$ at $f_{0}=$ $60 \mathrm{~Hz}$, which may become higher and cause flame extinction if $f_{0}$ is close to $50 \mathrm{~Hz}$.
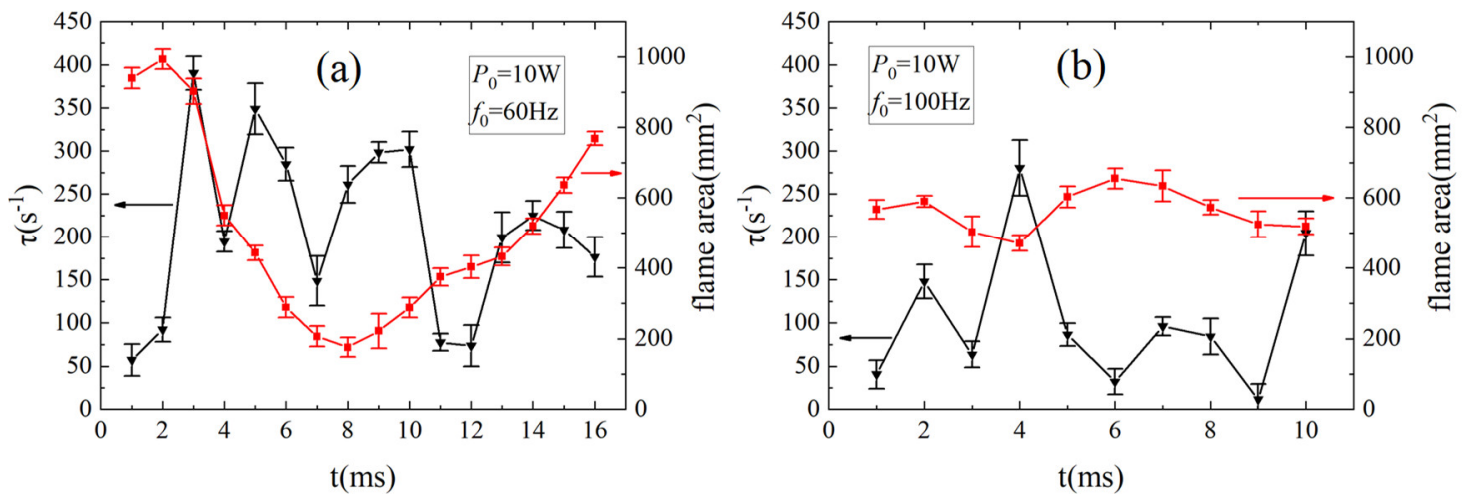

Fig. 6 Roughly estimated stretch rate based on temporal variation of relative flame surface area observed in the quartz tube ( $\Phi=0.65$, a: $f_{0}=60 \mathrm{~Hz}$, and b: $\left.f_{0}=100 \mathrm{~Hz}, P_{0}=10 \mathrm{~W}\right)$.

It was concluded that $f_{0}$ imposed a significant effect on the tubular flame stability. Acoustic perturbations below $f_{0}=210 \mathrm{~Hz}$ resulted in different flame behaviors, exhibiting a low-pass filter characteristic [37]. The perturbations with higher frequencies could be neglected to some extent. This phenomenon is different from the high frequency thermoacoustic oscillation occurred in premixed propane/air tubular flame [5], and partially premixed oxy-methane [18] and hydrogen/air swirl flames [17].

\subsection{Effects of acoustic power $P_{0}$}

In addition to the operating frequencies, the power of acoustics was also varied to explore its effects on flame stability. Here, $f_{0}$ was maintained at $180 \mathrm{~Hz}$ while $P_{0}$ was gradually increased from 1 to $20 \mathrm{~W}$ to examine the flame lift-off behaviors. Figure 7 illustrates that the anchored flame was gradually lifted as $P_{0}$ approached to $6 \mathrm{~W}$, and the lift-off height became larger as $P_{0}$ further increased. Around $P_{0}=20 \mathrm{~W}$, the flame was lifted to the exit of the quartz tube. Generally, the acoustic perturbation causes pressure and velocity fluctuations that may destroy the balance between the local flow velocity and flame speed, and subsequently induce the flame lift-off [38]. In 
addition, the extinction strain rate of the lean premixed $\mathrm{CH}_{4} /$ air swirl flame at $\Phi=0.65$ is relatively low (around $200 \mathrm{~s}^{-1}$ ) [39]. Local extinction may occur as the strain rate increases to approach extinction strain rate by increasing the power of acoustic generator. As a result, the increase in the acoustic power enhanced the flame lift-off and may even cause the flame to blow off.

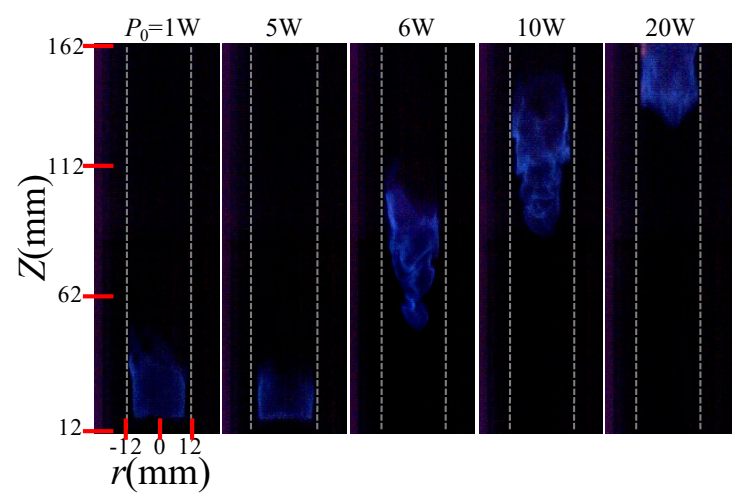

Fig. 7 Instantaneous flame images for the lean premixed $\mathrm{CH}_{4}$-air tubular flame forced by varied $P_{0}$ $\left(Q_{\mathrm{A}}=35 \mathrm{~L} / \mathrm{min}, f_{0}=180 \mathrm{~Hz}, P_{0}=1-20 \mathrm{~W}, \Phi=0.65\right)$.

When $P_{0}$ was below $5 \mathrm{~W}$, the flame was anchored at the bottom and showed stronger heat release rate and pressure fluctuations, as the fast Fourier transform (FFT) of $\mathrm{OH}^{*}$ chemiluminescence (Fig. 8(a)) and flame acoustic pressure fluctuations (Fig. 8(b)) illustrated. Here the normalized (divided by its corresponding mean value) $\mathrm{OH}^{*}$ chemiluminescence at the forcing frequency $(|\mathrm{FFT}|)$ was adopted to quantitatively indicate the effect of $P_{0}$ (insert picture) [40]. By increasing $P_{0}$ from 1 to $5 \mathrm{~W}$, the oscillation of $\mathrm{OH}^{*}$ chemiluminescence enhanced rapidly. However, as the flame was lifted off, the coupling effect was significantly weakened, probably attributed to the local flame extinction event [41]. The acoustic pressure fluctuation spectra present a similar trend, and therefore $\mathrm{OH}^{*}$ chemiluminescence is mainly employed in the rest of the paper. 

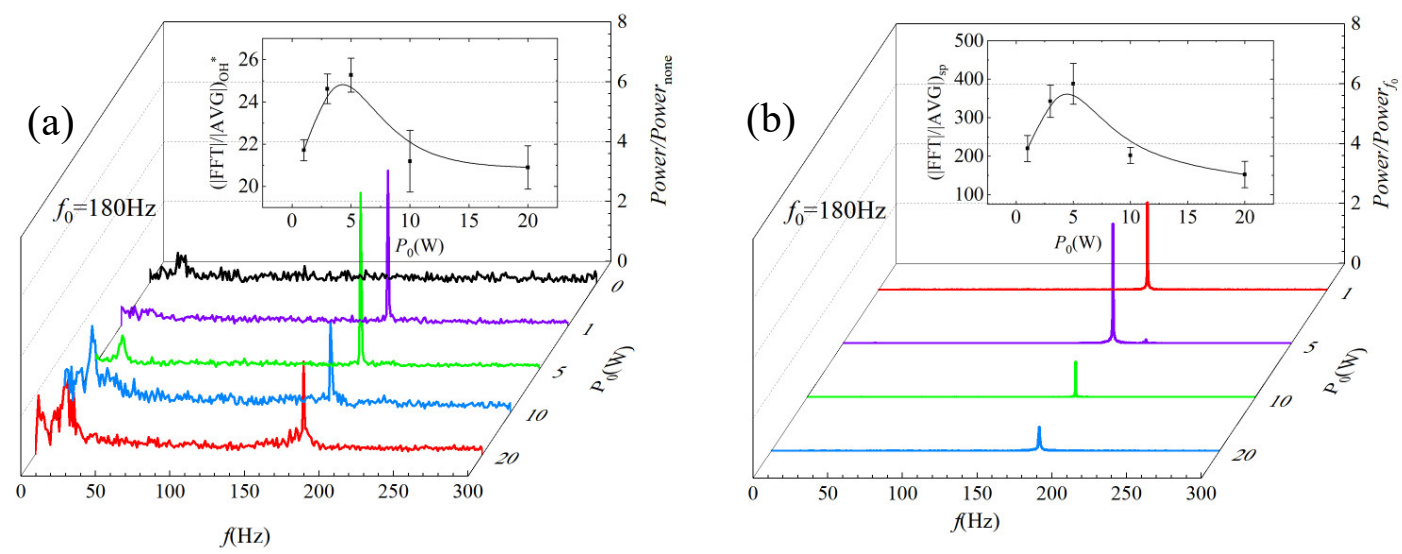

Fig. $8 \mathrm{OH}^{*}$ fluctuation spectra (a) and acoustic fluctuation spectra (b) for the lean premixed swirl tubular flame under different values of $P_{0}\left(Q_{\mathrm{A}}=35 \mathrm{~L} / \mathrm{min}, f_{0}=180 \mathrm{~Hz}, P_{0}=1-20 \mathrm{~W}, \Phi=0.65\right)$.

Flame responses to $60 \mathrm{~Hz}$ perturbations were then analyzed using $\mathrm{OH}^{*}$ fluctuation spectra. As presented in Fig. 9, the flame oscillation gradually enhanced when $P_{0}$ was increased from 1 to $20 \mathrm{~W}$ which may tend to saturate when $P_{0}$ exceeded $20 \mathrm{~W}$. However, owing to the limitation of the current apparatus, such test has not yet been conducted.

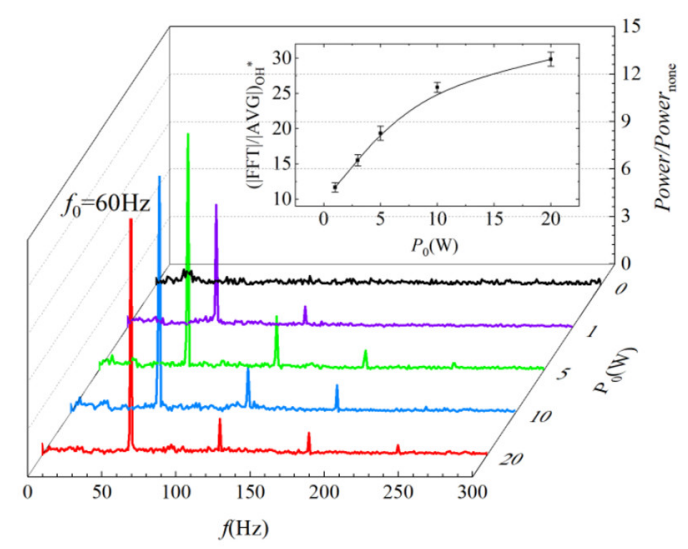

Fig. $9 \mathrm{OH}^{*}$ fluctuation spectra for the lean premixed swirl tubular flame under varied $P_{0}\left(Q_{\mathrm{A}}=35\right.$ $\left.\mathrm{L} / \min , f_{0}=60 \mathrm{~Hz}, P_{0}=1-20 \mathrm{~W}, \Phi=0.65\right)$.

These results indicate that acoustic perturbations with ultra-low power, i.e., $P_{0}=1 \mathrm{~W}$, can force the tubular flame to oscillate, and increasing $P_{0}$ generally intensifies the oscillation. On the other hand, the increase of the perturbating frequency will also change the flame dynamics, however, the flame responses may be different under different values of $P_{0}$. To illustrate it, the 
combustion regime diagram with $P_{0}=5 \mathrm{~W}$ has been added as a representative, as shown in Fig. 10. In comparison with that of $P_{0}=10 \mathrm{~W}$ (Fig. 3), the regions where the flame was lifted-off and extinguished in Fig. 3 evolved to a region of anchored flame with intense oscillation in Fig. 10. The critical values of $f_{0}$ separating different regions also vary slightly in these two cases. Furthermore, our tests illustrated that the flame perturbated by a higher power of $P_{0}>10 \mathrm{~W}$ responses similarly as that of $P_{0}=10 \mathrm{~W}$.

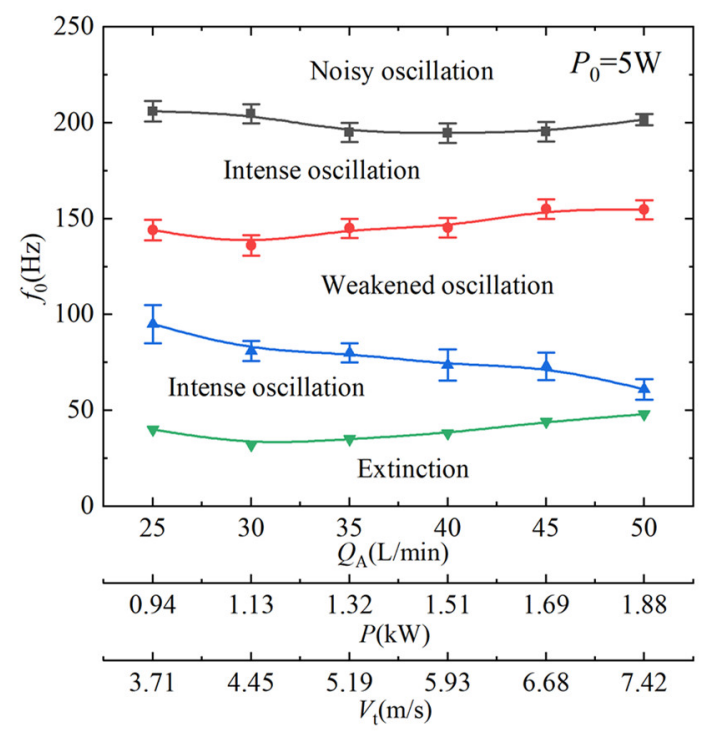

Fig. 10 Combustion regime diagram for the lean premixed swirl tubular flame under acoustic perturbations of $P_{0}=5 \mathrm{~W}(\Phi=0.65)$.

\subsection{Effects of air flow rate $Q_{\mathrm{A}}$}

Finally, the air flow rate was varied to examine the flame responses to acoustic perturbations. Two typical conditions at $f_{0}=180$ and $60 \mathrm{~Hz}$ were investigated with $P_{0}=10 \mathrm{~W}$, as indicated in Figs. 11 and 12 , respectively. In the case of $f_{0}=180 \mathrm{~Hz}$, as $Q_{\mathrm{A}}$ increased, the lift-off height decreased. It can be verified by the instantaneous flame images at $Q_{\mathrm{A}}=25$ and $35 \mathrm{~L} / \mathrm{min}$ shown in Fig. 11(a) and 11(b), respectively. The bold dash curves indicate the positions of the flame front. Corresponding velocity distribution, which is an average value of 50 instantaneous results at the same periodical instant, has also been illustrated. The velocity distribution indicates that the increase in the flow rate enhances inner gas recirculation and therefore leads to the decrease of lift-off height.

In the case of $f_{0}=60 \mathrm{~Hz}$, by increasing $Q_{\mathrm{A}}$, the length of the flame increased (Fig. 12(a)). The 
interaction between flame and acoustics was intensified when $Q_{\mathrm{A}}$ was increased from 25 to 35 $\mathrm{L} / \mathrm{min}$ according to $\mathrm{OH}^{*}$ fluctuation spectra shown in Fig. 12 (b). However, the $\mathrm{OH}^{*}$ fluctuation intensity becomes weakened as $Q_{\mathrm{A}}$ increases from 35 to $50 \mathrm{~L} / \mathrm{min}$.

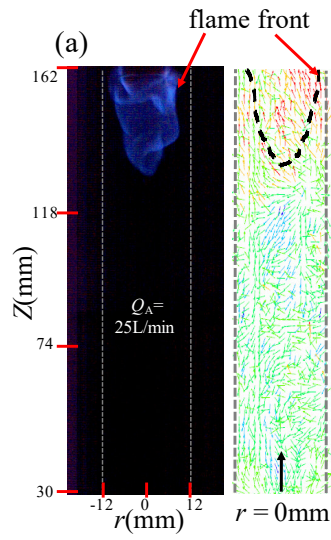

(b)

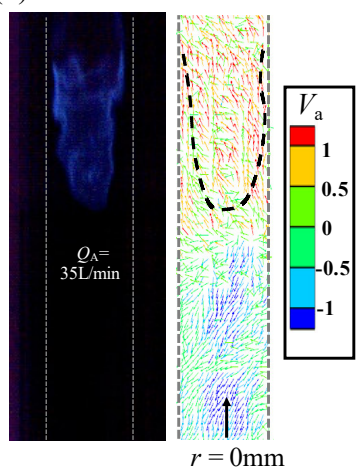

Fig. 11 Instantaneous flame images and corresponding velocity distributions for the lean premixed swirl tubular flame with perturbation at $f_{0}=180 \mathrm{~Hz}, P_{0}=10 \mathrm{~W}$ under different flow rates $\left(Q_{\mathrm{A}}=25\right.$ and $35 \mathrm{~L} / \mathrm{min}, \Phi=0.65)$.
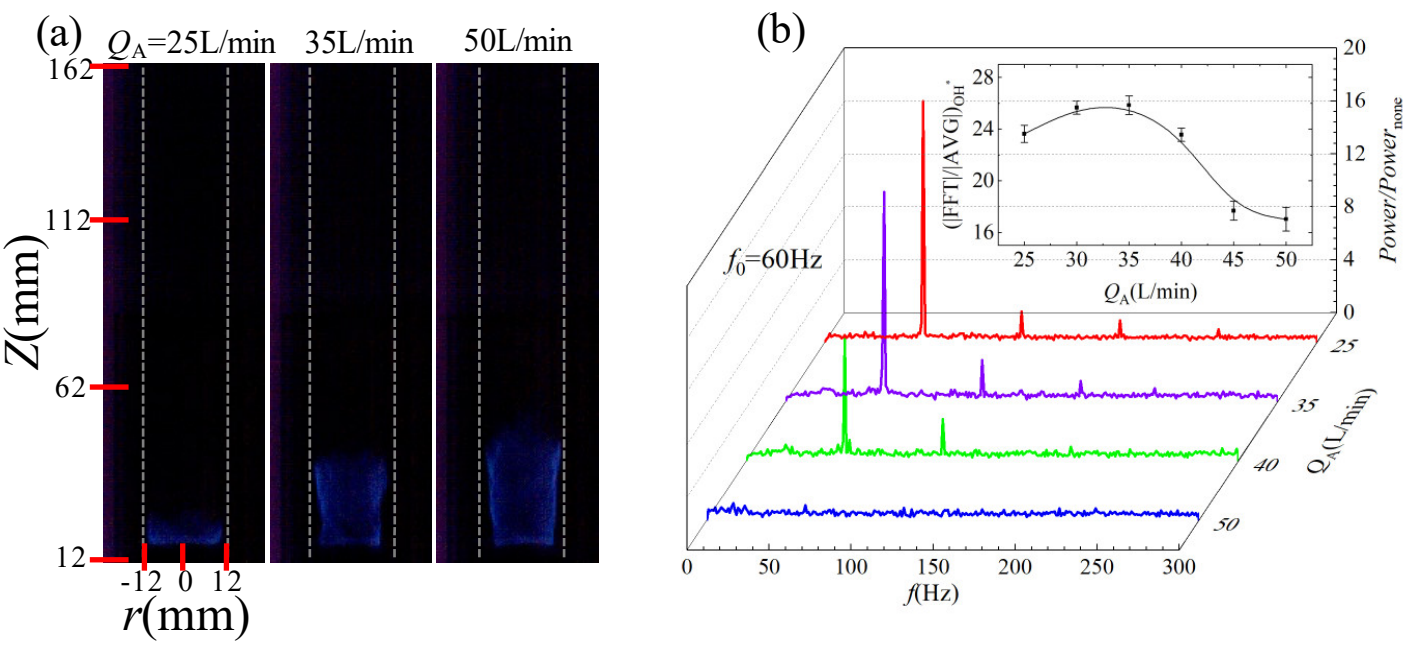

Fig. 12 Instantaneous flame images (a) and $\mathrm{OH}^{*}$ fluctuation spectra (b) for the lean premixed swirl tubular flame under different flow rates $\left(f_{0}=60 \mathrm{~Hz}, P_{0}=10 \mathrm{~W}, Q_{\mathrm{A}}=25-50 \mathrm{~L} / \mathrm{min}, \Phi=0.65\right)$.

\section{Discussion based on POD analysis}

To understand the repeatable acoustics forced flame dynamics in more detail, such as the flame lift-off and intensifying or weakening oscillation under a variety of operation conditions, a 
spatio-temporal POD analysis was applied to the flame images taken by the high-speed video camera (1000 fps). The POD analysis has been explored to investigate either the thermoacoustic instability in a gas turbine model combustor [42-44] or in engine combustion $[45,46]$. Here a brief mathematical description of the POD theory used in this research is outlined. More details of the general POD technique are available in the literature [47].

The fundamental idea of POD is to decompose a set of scalar quantities distributions $\boldsymbol{S}^{(k)}=(s)_{i, j}^{(k)}$ into a linear combination of $m^{\text {th }}$ order space-dependent functions and time-dependent coefficients in the form of, for example,

$$
\boldsymbol{S}^{(k)}=\sum_{m=1}^{M} c_{m}^{(k)} \varphi_{m}
$$

where $\varphi_{m}(m=1,2 \ldots \mathrm{M})$ are the basic functions which are orthonormal to each other, $c_{m}^{(k)}$ is the POD coefficient of $m^{\text {th }}$ mode, $M$ is the overall number of selected modes. In the present study, the flame luminosity in gray-scale is selected as the scalar quantity distribution $(s)_{i, j}^{(k)}$, in which $i$ and $j$ are pixel positions in $Z$ and $r$ directions respectively, $k$ is the snapshot index [48-50]. Here 200 successive gray-scale flame images (more than 10 cycles) were used to analyze the cyclical variation.

The coefficient matrix can be obtained as

$$
c_{m}^{(k)}=\left[\begin{array}{cccc}
c_{1}^{(1)} & c_{2}^{(1)} & \ldots & c_{M}^{(1)} \\
c_{1}^{(2)} & c_{2}^{(2)} & \ldots & c_{M}^{(2)} \\
\ldots & \ldots & \ldots & \ldots \\
c_{1}^{(K)} & c_{2}^{(K)} & \ldots & c_{M}^{(K)}
\end{array}\right]
$$

The detailed derivation of formula (2) is provided in the supporting information. Each row in matrix $c_{m}^{(k)}$ represents POD coefficients of the same mode at different instants, and each column represents POD coefficients of different modes at the same instant. Then the cumulative energy fraction of the first $m$ modes $\left(K E_{m}\right)$ can be expressed as

$$
K E_{m}=\frac{1}{2} \sum_{k=1}^{K}\left(c_{m}^{(k)}\right)^{2}, k=1,2, \ldots, 200
$$


The energy fraction of $m^{\text {th }}$ mode $\left(k e_{m}\right)$ can be given as

$$
k e_{m}=K E_{m} / \sum_{m=1}^{M} K E_{m}
$$

The energy fraction, as a very important parameter in POD analysis, represents the contribution of each mode to the flame dynamics, and a higher value indicates a greater effect. Theoretically, the first mode of POD represents the ensemble average flame pattern and therefore contains most of the energy in the fluctuating flame. The energy fraction decreases as the mode number increases [45,51-52].

Here POD is employed to mainly investigate the flame lift-off behavior. Under fixed values of $P_{0}=10 \mathrm{~W}$ and $Q_{\mathrm{A}}=35 \mathrm{~L} / \mathrm{min}$, the cumulative energy fractions of the 200 modes for different frequencies are presented in Fig.13. As the locally enlarged curves illustrated, the first six modes contribute over $99 \%$ of the total energy, and hence the contributions of the remaining modes can be neglected.

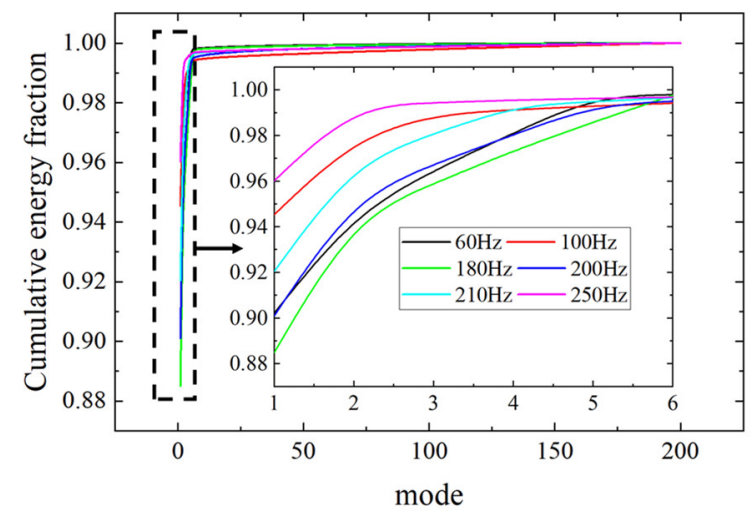

Fig. 13 Cumulative energy fraction for the lean premixed swirl tubular flame perturbed under different frequencies $\left(P_{0}=10 \mathrm{~W}, Q_{\mathrm{A}}=35 \mathrm{~L} / \mathrm{min}, \Phi=0.65\right)$. 


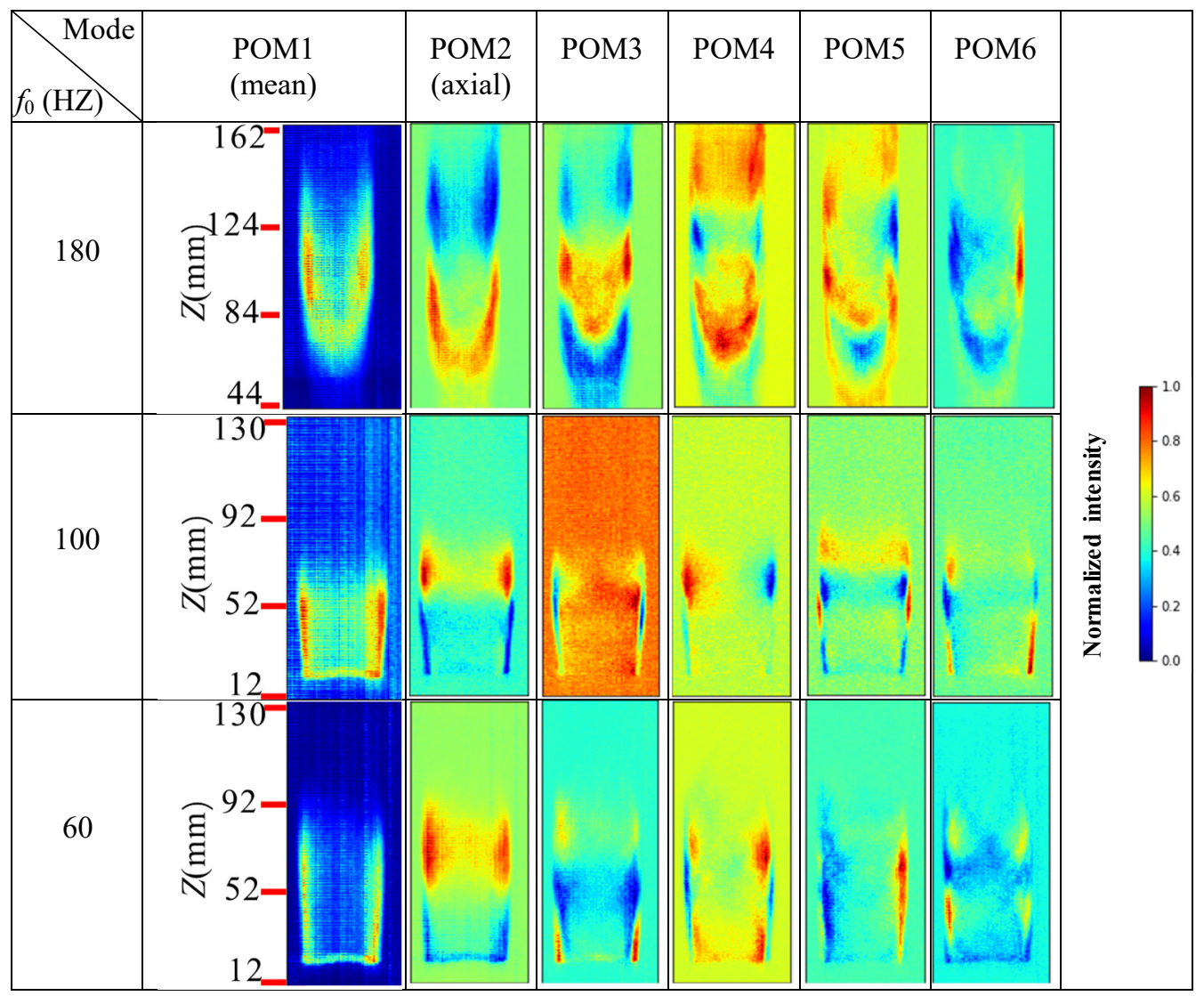

Fig. 14 Contours for the first six POD modes for 200-image sets for the lean premixed swirl tubular flame under different frequencies $\left(P_{0}=10 \mathrm{~W}, Q_{\mathrm{A}}=35 \mathrm{~L} / \mathrm{min}, \Phi=0.65\right)$.

The first six modes (denoted as POM1 to POM6) are presented in Fig. 14 (256*625 pixels) to identify the variations of flame responses under different acoustic frequencies of $f_{0}=60,100$ and $180 \mathrm{~Hz}$. For each case, as the most dominant part, POM1 is assumed to represent the mean flame pattern, i.e., flame scale and shape, and the remaining modes contain the fluctuating part $[51,52]$. With axisymmetric distribution, POM2 indicates an axial nature of the flame fluctuation. For $f_{0}=$ $180 \mathrm{~Hz}$, the axial nature (POM2) evolves to the circumferential nature at POM6; while for those of $f_{0}=60$ and $100 \mathrm{~Hz}$, circumferential nature is firstly observed at POM5 and POM4, respectively. The evolution from POM3 to the mode representing circumferential fluctuation is regarded as the transition part. Hence, four parts, representing mean (POM1), axial (POM2), circumferential and transition can be defined, which is similar to Refs. $[53,54]$.

Figure 15 illustrates the specific contributions of the first six modes to examine flame behaviors under different $f_{0}$. The contribution of each part representing mean, axial, transition and 
circumferential nature respectively is also shown. It should be noted that the energy fraction of the modes after the circumferential part is ultralow, and such contribution has been counted into the circumferential part in Fig. 15. As counted in Fig. 15(a), POM1 contributes 90.2\%, 94.5\% and 88.5\% of the total energy for the cases of $f_{0}=60,100$ and $180 \mathrm{~Hz}$, respectively. The case of $f_{0}=100 \mathrm{~Hz}$ has the highest mean part (POM1), resulting in the lowest contribution of the fluctuating part and therefore the weakest flame oscillation. At $f_{0}=60$ and $180 \mathrm{~Hz}$, POM2 contributes $4.33 \%$ and $5.89 \%$ of the total energy, respectively. The higher energy fraction of POM2 in $f_{0}=180 \mathrm{~Hz}$ indicates stronger axial fluctuations, which may lead to the flame lift-off.
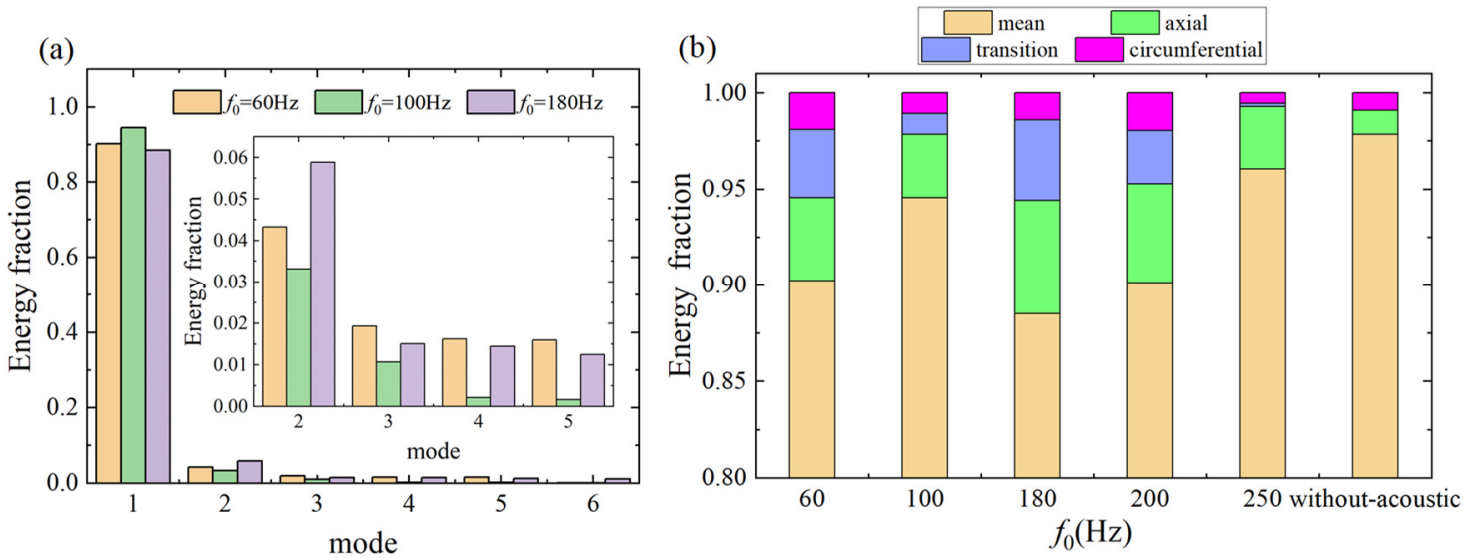

Fig. 15 Energy fractions for POD analysis for the lean premixed swirl tubular flame under different frequencies $\left(P_{0}=10 \mathrm{~W}, Q_{\mathrm{A}}=35 \mathrm{~L} / \mathrm{min}, \Phi=0.65\right)$.

The evolutions from mean to circumferential parts are examined in Fig. 15(b) for the cases of $f_{0}=60-250 \mathrm{~Hz}$. For comparison, the result for flame without acoustic perturbation is also illustrated in the last column. Its axial part (POM2) turns to the circumferential part in the $3^{\text {rd }}$ mode (POM3). The mean part occupies $97.9 \%$, indicating a steady tubular flame. In the case of $f_{0}=250$ $\mathrm{Hz}$, the mean part contributes $96.0 \%$, resulting in very weak fluctuations dominated by the axial part. Such perturbation to the flame response is recognized as noisy oscillation. In the case of $f_{0}=$ $200 \mathrm{~Hz}$, the energy fraction of the mean part reduces to $90.1 \%$ and that of the axial part increases to $5.16 \%$, forcing the tubular flame to lift off. As $f_{0}$ further decreases to $180 \mathrm{~Hz}$, the energy fraction of the axial part increases to $5.89 \%$, for which the flame is located near the tube exit. In the case of $f_{0}=$ $100 \mathrm{~Hz}$, the mean part of $94.5 \%$ and the axial part of $3.31 \%$ indicate weakened oscillations. In the 
case of $f_{0}=60 \mathrm{~Hz}$, the contribution of the axial part $(4.32 \%)$ is relatively lower compared with that of $f_{0}=180 \mathrm{~Hz}$, and hence the flame is not lifted off; comparing with that of $f_{0}=100 \mathrm{~Hz}$, the contributions of the transition $(3.56 \%)$ and circumferential parts $(1.89 \%)$ are stronger, presenting intense oscillations.

Following the aforementioned analysis, it is reasonable to propose the hypothesis of a $5.0 \%$ energy fraction of axial part (POM2) as the critical indicator for flame lift-off in the present study. To support it, 17 tests have been examined by varying $f_{0}, P_{0}$ and $Q_{\mathrm{A}}$. The specific conditions are listed in Table 1 . The results certify that as the energy fraction of POM2 exceeds $5.0 \%$, the flame is lifted off, and below $5.0 \%$, the flame is anchored regardless of $f_{0}, P_{0}$, and $Q_{\mathrm{A}}$. Particularly, in Case 9 $\left(f_{0}=180 \mathrm{~Hz}, P_{0}=5 \mathrm{~W}\right.$ and $\left.Q_{\mathrm{A}}=35 \mathrm{~L} / \mathrm{min}\right)$ where the flame is anchored, the energy fraction of POM2 is $4.94 \%$ that approaches to the critical value. However, when $P_{0}$ is increased to $6 \mathrm{~W}$ and subsequently the energy fraction raises to $5.11 \%$, flame lift-off occurs (Fig. 7), verifying that the $5.0 \%$ energy fraction of axial mode (POM 2) is a good criterion to predict the flame lift-off of the lean premixed swirl tubular flame.

Furthermore, when the air flow rate increases from 25 to $50 \mathrm{~L} / \mathrm{min}$, the evolution of intense oscillations to weakened ones at $f_{0}=60 \mathrm{~Hz}$ can also be interpreted by the variations of mean, axial and circumferential parts from the POD analysis (Fig. S2).

\section{Conclusions}

In this study, the response of a lean premixed methane/air (equivalence ratio of 0.65 ) swirl tubular flame to longitudinal acoustics perturbations was experimentally studied. Detailed measurements on the flame stability, flame structure, $\mathrm{OH}^{*}$ chemiluminescence, acoustic pressure fluctuation and flow velocity were carried out to investigate the effects of the acoustic frequency $\left(f_{0}\right)$ and power $\left(P_{0}\right)$ as well as air flow rate $\left(Q_{\mathrm{A}}\right)$. POD technique was employed to examine the evolution of fluctuation mode to interpret the flame behaviors. The results indicate that $f_{0}$ plays a more dominant role over $P_{0}$ and $Q_{\mathrm{A}}$ in determining the flame responses to acoustic perturbations. 
Table1 Tests for the analysis of flame lift-off behavior $(\Phi=0.65)$

\begin{tabular}{|c|c|c|c|c|c|}
\hline Case & $\begin{array}{l}\text { Frequency } \\
f_{0}(\mathrm{~Hz})\end{array}$ & $\begin{array}{l}\text { Power } \\
P_{0}(\mathrm{~W})\end{array}$ & $\begin{array}{c}\text { Air flow rate } \\
Q_{\mathrm{A}}(\mathrm{L} / \mathrm{min})\end{array}$ & $\begin{array}{c}\text { Energy Fraction } \\
\text { POM2 }\end{array}$ & $\begin{array}{c}\text { Lift -off condition } \\
\text { (YES or NO) }\end{array}$ \\
\hline 1 & 60 & 1 & 35 & $2.89 \%$ & $\mathrm{NO}$ \\
\hline 2 & 60 & 5 & 35 & $3.64 \%$ & $\mathrm{NO}$ \\
\hline 3 & 60 & 10 & 35 & $4.33 \%$ & $\mathrm{NO}$ \\
\hline 4 & 60 & 20 & 35 & $4.40 \%$ & NO \\
\hline 5 & 60 & 10 & 25 & $3.63 \%$ & $\mathrm{NO}$ \\
\hline 6 & 60 & 10 & 50 & $4.64 \%$ & NO \\
\hline 7 & 100 & 10 & 35 & $3.32 \%$ & $\mathrm{NO}$ \\
\hline 8 & 180 & 1 & 35 & $2.58 \%$ & $\mathrm{NO}$ \\
\hline 9 & 180 & 5 & 35 & $4.94 \%$ & NO \\
\hline 10 & 180 & 6 & 35 & $5.11 \%$ & YES \\
\hline 11 & 180 & 10 & 35 & $5.89 \%$ & YES \\
\hline 12 & 180 & 20 & 35 & $6.13 \%$ & YES \\
\hline 13 & 180 & 10 & 25 & $6.33 \%$ & YES \\
\hline 14 & 180 & 10 & 50 & $5.52 \%$ & YES \\
\hline 15 & 200 & 10 & 35 & $5.16 \%$ & YES \\
\hline 16 & 210 & 10 & 35 & $4.77 \%$ & NO \\
\hline 17 & 250 & 10 & 35 & $3.26 \%$ & $\mathrm{NO}$ \\
\hline
\end{tabular}

The laminar tubular flame is sensitive to perturbations below $f_{0}=210 \mathrm{~Hz}$. As $f_{0}$ approaches to $200 \mathrm{~Hz}$, an intense flame oscillation appears at low $P_{0}$; such intense oscillations evolve to flame lift-off between $f_{0}=170$ and $200 \mathrm{~Hz}$ as $P_{0}$ increases, and the flame blows off between $f_{0}=150$ and $165 \mathrm{~Hz}$. A weakened oscillation is observed between $f_{0}=100$ and $150 \mathrm{~Hz}$, and such a region gradually widens as $Q_{\mathrm{A}}$ increases. Around $f_{0}=50-100 \mathrm{~Hz}$, an anchored flame with intense oscillation appears, and below $f_{0}=50 \mathrm{~Hz}$, the flame cannot be sustained even under ultra-weak acoustic perturbations. POD analysis illustrates that the flame response is determined by the contribution of the mean part and the evolution of fluctuations among axial, circumferential and transition modes. A much high energy fraction of the mean part brings noisy or weakened 
oscillations, while the axial mode fluctuation dominates the flame responses, and its energy fraction of $5.0 \%$ is found to be a critical condition for flame lift-off (above 5.0\%). In practical applications, the low frequency perturbations that induce intense oscillation as well as extinction, and the moderate frequency perturbations that result in flame lift-off or blow off, should be carefully treated in the lean swirl tubular flame.

\section{Supporting Information}

The optical configuration of the PIV system (Fig. S1); Energy fractions from POD analysis under different air flow rates (Fig. S2).

\section{Acknowledgments}

This study is supported by National Natural Science Foundation of China (No. 91641204 and No. 51676016). Dr. Dan Zhao's work was supported by the National Research Foundation, Prime Minister's Office, Singapore with Grant No. NRF2016NRF-NSFC001-102.

\section{References}

[1] S. Ishizuka, Characteristics of tubular flames, Prog. Energy Combust. Sci. 19 (1993) 187-226. https://doi.org/10.1016/0360-1285(93)90015-7.

[2] S. Ishizuka, R. Hagiwara, M. Suzuki, A. Nakmura, O. Hamaguchi, Combustion characteristics of a tubular flame burner, Japan Soc. Mech. Engrs. 65 (1999) 3845-3852.

[3] B. Shi, J. Hu, S. Ishizuka, Carbon dioxide diluted methane/oxygen combustion in a rapidly mixed tubular flame burner, Combust. Flame. 162 (2015) 420-430. https://doi.org/10.1016/j.combustflame.2014.07.022. 
[4] D. Shimokuri, S. Ishizuka, Flame stabilization with a tubular flame, Proc. Combust. Inst. 30 (2005) 399-406. https://doi.org/10.1016/j.proci.2004.08.007.

[5] D. Shimokuri, Y. Shiraga, K. Ishii, H. Toh, S. Ishizuka, An experimental study on the high frequency oscillatory combustion in tubular flame burners, Combust. Flame. 161 (2014) 2025-2037. https://doi.org/10.1016/j.combustflame.2014.01.027.

[6] K. Yamamoto, T. Hirano, S. Ishiuka, Effects of pressure diffusion on the characteristics of tubular flames, Symp. Combust. 26 (1996) 1129-1135.

https://doi.org/10.1016/S0082-0784(96)80328-6.

[7] Y. Zhang, S. Ishizuka, H. Zhu, R.J. Kee, Effects of stretch and pressure on the characteristics of premixed swirling tubular methane-air flames, Proc. Combust. Inst. 32 (2009) 1149-1156. https://doi.org/10.1016/j.proci.2008.06.066.

[8] Y. Zhang, S. Ishizuka, H. Zhu, R.J. Kee, The effects of rotation rate on the characteristics of premixed propane-air swirling tubular flames, Proc. Combust. Inst. 31 (2007) 1101-1107. https://doi.org/10.1016/j.proci.2006.07.030.

[9] R.J. Kee, A.M. Colclasure, H. Zhu, Y. Zhang, Modeling tangential injection into ideal tubular flames, Combust. Flame. 152 (2008) 114-124.

https://doi.org/10.1016/j.combustflame.2007.07.019.

[10] S. Ishizuka, D. Dunn-Rankin, R.W. Pitz, R.J. Kee, Y. Zhang, T. Takeno, D. Shimokuri, Tubular combustion, Momentum Press, New York, 2013.

[11] R. Mattioli, T.K. Pham, D. Dunn-rankin, Secondary air injection in miniature liquid fuel film combustors, Proc. Combust. Inst. 32 (2009) 3091-3098.

https://doi.org/10.1016/j.proci.2008.06.174.

[12] Y. Feng, W. Qi, M.H. Baghaei, Y. Zhang, D. Zhao, Investigation on a novel type of tubular flame burner with multi-stage partially-premixing features for liquid-fueled gas turbine, 2202 (2019). https://doi.org/10.1080/00102202.2019.1651298.

[13] D. Shimokuri, Y. Taomoto, R. Matsumoto, Development of a powerful miniature power 
system with a meso-scale vortex combustor, Proc. Combust. Inst. 36 (2017) 4253-4260. https://doi.org/10.1016/j.proci.2016.06.180.

[14] S. Ishizuka, T. Motodamari, D. Shimokuri, Rapidly mixed combustion in a tubular flame burner, Proc. Combust. Inst. 31 (2007) 1085-1092. https://doi.org/10.1016/j.proci.2006.07.128.

[15] B. Shi, J. Hu, H. Peng, S. Ishizuka, Effects of internal flue gas recirculation rate on the NOx emission in a methane/air premixed flame, Combust. Flame. 188 (2018) 199-211. https://doi.org/10.1016/j.combustflame.2017.09.043.

[16] J. Wei, Y. Ren, Y. Zhang, B. Shi, S. Li, Effects of temperature-time history on the flame synthesis of nanoparticles in a swirl-stabilized tubular burner with two feeding modes, J. Aerosol Sci. 133 (2019) 72-82. https://doi.org/10.1016/j.jaerosci.2019.04.002.

[17] B. Shi, B. Li, X. Zhao, R. Chen, O. Fujita, N. Wang, Rapidly mixed combustion of hydrogen/oxygen diluted by $\mathrm{N}_{2}$ and $\mathrm{CO}_{2}$ in a tubular flame combustor, Int. J. Hydrogen Energy. 43 (2018) 14806-14815. https://doi.org/10.1016/j.ijhydene.2018.06.068.

[18] B. Li, B. Shi, X. Zhao, K. Ma, D. Xie, D. Zhao, J. Li, Oxy-fuel combustion of methane in a swirl tubular flame burner under various oxygen contents: Operation limits and combustion instability, Exp. Therm. Fluid Sci. 90 (2018) 115-124. https://doi.org/10.1016/j.expthermflusci.2017.09.001.

[19] B. Shi, W. Peng, B. Li, J. Hu, N. Wang, S. Ishizuka, $\mathrm{CO}_{2}$ diluted propane/oxygen combustion in a rapidly mixed tubular flame burner, Proc. Combust. Inst. 36 (2017) 4261-4268. https://doi.org/10.1016/j.proci.2016.06.112.

[20] S.W. Shopoff, P. Wang, R.W. Pitz, Experimental study of cellular instability and extinction of non-premixed opposed-flow tubular flames, Combust. Flame. 158 (2011) 2165-2177. https://doi.org/10.1016/j.combustflame.2011.04.007.

[21] S. Hu, R.W. Pitz, Y. Wang, Extinction and near-extinction instability of non-premixed tubular flames, Combust. Flame. 156 (2009) 90-98. 
https://doi.org/10.1016/j.combustflame.2008.09.004.

[22] Y. Ren, S. Li, W. Cui, Y. Zhang, L. Ma, Low-frequency AC electric field induced thermoacoustic oscillation of a premixed stagnation flame, Combust. Flame. 176 (2017) 479-488.

https://doi.org/10.1016/j.combustflame.2016.11.013.

[23] P. Palies, T. Schuller, D. Durox, S. Candel, Modeling of premixed swirling flames transfer functions, Proc. Combust. Inst. 33 (2011) 2967-2974.

https://doi.org/10.1016/j.proci.2010.06.059.

[24] P. Palies, D. Durox, T. Schuller, S. Candel, Nonlinear combustion instability analysis based on the flame describing function applied to turbulent premixed swirling flames, Combust. Flame. 158 (2011) 1980-1991. https://doi.org/10.1016/j.combustflame.2011.02.012.

[25] T. Smith, B. Emerson, W. Proscia, T. Lieuwen, Role of induced axial acoustics in transverse acoustic flame response, Combust. Flame. 195 (2018) 140-150. https://doi.org/10.1016/j.combustflame.2017.12.035.

[26] A. Saurabh, C.O. Paschereit, Dynamics of premixed swirl flames under the influence of transverse acoustic fluctuations, Combust. Flame. 182 (2017) 298-312. https://doi.org/10.1016/j.combustflame.2017.04.014.

[27] S. Chaudhuri, B.M. Cetegen, Blowoff characteristics of bluff-body stabilized conical premixed flames with upstream spatial mixture gradients and velocity oscillations, Combust. Flame. 153 (2008) 616-633. https://doi.org/10.1016/j.combustflame.2007.12.008.

[28] A.A. Chaparro, B.M. Cetegen, Blowoff characteristics of bluff-body stabilized conical premixed flames under upstream velocity modulation, Combust. Flame. 144 (2006) 318-335. https://doi.org/10.1016/j.combustflame.2005.08.024.

[29] S. Chaudhuri, S. Kostka, M.W. Renfro, B.M. Cetegen, Blowoff mechanism of harmonically forced bluff body stabilized turbulent premixed flames, Combust. Flame. 159 (2012) 638-640. https://doi.org/10.1016/j.combustflame.2011.08.005. 
[30] K.S. Kedia, A.F. Ghoniem, The response of a harmonically forced premixed flame stabilized on a heat-conducting bluff-body, Proc. Combust. Inst. 35 (2015) 1065-1072. https://doi.org/10.1016/j.proci.2014.06.007.

[31] D. Demare, F. Baillot, Acoustic enhancement of combustion in lifted nonpremixed jet flames, Combust. Flame. 139 (2004) 312-328. https://doi.org/10.1016/j.combustflame.2004.09.004.

[32] R.W. Pitz, S. Hu, P. Wang, Tubular premixed and diffusion flames: Effect of stretch and curvature, Prog. Energy Combust. Sci. 42 (2014) 1-34. https://doi.org/10.1016/j.pecs.2014.01.003.

[33] B. Shi, J. Hu, H. Peng, S. Ishizuka, Flow visualization and mixing in a rapidly mixed type tubular flame burner, Exp. Therm. Fluid Sci. 54 (2014) 1-11. https://doi.org/10.1016/j.expthermflusci.2014.01.009.

[34] C. F. Silva, M. Merk, T. komarek, Wolfgang Polifke, The contribution of intrinsic thermoacoustic feedback to combustion noise and resonances of a confined turbulent premixed flame, Combust. Flame. 182 (2017) 269-278. https://doi.org/10.1016/j.combustflame.2017.04.015.

[35] X. Zhao, B. Shi, W. Peng, Q. Cao, D. Xie, W. Dong, N. Wang, Effects of $\mathrm{N}_{2}$ and $\mathrm{CO}_{2}$ dilution on the combustion characteristics of $\mathrm{C}_{3} \mathrm{H}_{8} / \mathrm{O}_{2}$ mixture in a swirl tubular flame burner, Exp. Therm. Fluid Sci. 100 (2019) 251-258. https://doi.org/10.1016/j.expthermflusci.2018.09.009.

[36] J. Gao, C. Kong, J. Zhu, A. Ehn, T. Hurtig, Y. Tang, S. Chen, M. Aldén, Z. Li, Visualization of instantaneous structure and dynamics of large-scale turbulent flames stabilized by a gliding arc discharge, Proc. Combust.Inst. 37( 2019) 5629-5636.

https://doi.org/10.1016/j.proci.2018.06.030.

[37] U. Idahosa, A. Saha, C. Xu, S. Basu, Non-premixed acoustically perturbed swirling flame dynamics, Combust. Flame. 157 (2010) 1800-1814. https://doi.org/10.1016/j.combustflame.2010.05.008.

[38] Q.An, W.Y. Kwong, B. D.Geraedts, A. M. Steinberg, coupled dynamics of lifted-off and 
processing vortex core formation in swirl flame, Combust. Flame. 168 (2016) 228-239.

https://doi.org/10.1016/j.combustflame.2016.03.011.

[39] Z. Chen, Y. Ju, Combined effects of curvature, radiation, and stretch on the extinction of premixed tubular flames, Int. J. Heat Mass Transfer, 51(208) 6118-6125.

https://doi.org/10.1016/j.ijheatmasstransfer.2008.05.002.

[40] R. Balachandran, B.O. Ayoola, C.F. Kaminski, A.P. Dowling, E. Mastorakos, Experimental investigation of the nonlinear response of turbulent premixed flames to imposed inlet velocity oscillations, Combust. Flame. 143 (2005) 37-55.

https://doi.org/10.1016/j.combustflame.2005.04.009.

[41] B.D. Bellows, Y. Neumeier, T. Lieuwen, Forced response of a swirling, premixed flame to flow disturbances, J. Propuls. Power. 22 (2006) 1075-1084. https://doi.org/10.2514/1.17426.

[42] A.M. Steinberg, I. Boxx, M. Stöhr, W. Meier, C.D. Carter, Effects of flow structure dynamics on thermoacoustic instabilities in swirl-stabilized combustion, AIAA J. 50 (2012) 952-967. https://doi.org/10.2514/1.J051466.

[43] A.M. Steinberg, I. Boxx, M. Stöhr, C.D. Carter, W. Meier, Flow-flame interactions causing acoustically coupled heat release fluctuations in a thermo-acoustically unstable gas turbine model combustor, Combust. Flame. 157 (2010) 2250-2266.

https://doi.org/10.1016/j.combustflame.2010.07.011.

[44] A.M. Steinberg, C.M. Arndt, W. Meier, Parametric study of vortex structures and their dynamics in swirl-stabilized combustion, Proc. Combust. Inst. 34 (2013) 3117-3125. https://doi.org/10.1016/j.proci.2012.05.015.

[45] H. Chen, D.L. Reuss, D.L.S. Hung, V. Sick, A practical guide for using proper orthogonal decomposition in engine research, Int. J. Engine Res. 14 (2013) 307-319. https://doi.org/10.1177/1468087412455748.

[46] K. Bizon, G. Continillo, E. Mancaruso, S.S. Merola, B.M. Vaglieco, POD-based analysis of combustion images in optically accessible engines, Combust. Flame. 157 (2010) 632-640. 
https://doi.org/10.1016/j.combustflame.2009.12.013.

[47] W.K.G. Mark N. Glauser, Stewart J. Leib, Coherent Structures in the Axisymmetric Turbulent Jet Mixing Layer, Springer Berlin Heidelberg, 1987.

[48] R.S. Troy, M. Jeff, H. Philip, Low-Dimensional Modelling of Turbulence Using the Proper Orthogonal Decomposition: A Tutorial, Nonlinear Dyn. (2005) 275-307.

[49] L. Sirovich, Turbulence and the dynamics of coherent structures. I. Coherent structures, Q. Appl. Math. 45 (1987) 561-571. https://doi.org/10.1090/qam/910462.

[50] L. Sirovich, Turbulence and the dynamics of coherent structures II:symmetries and transformations, Q. Appl. Math. XLV (1987) 573-582.

[51] H. Chen, M. Xu, D.L.S. Hung, H. Zhuang, Cycle-to-cycle variation analysis of early flame propagation in engine cylinder using proper orthogonal decomposition, Exp. Therm. Fluid Sci. 58 (2014) 48-55. https://doi.org/10.1016/j.expthermflusci.2014.06.017.

[52] A.G. Charalambides, S. Sahu, Y. Hardalupas, A.M.K.P. Taylor, Y. Urata, Evaluation of Homogeneous Charge Compression Ignition (HCCI) autoignition development through chemiluminescence imaging and Proper Orthogonal Decomposition, Appl. Energy. 210 (2018) 288-302. https://doi.org/10.1016/j.apenergy.2017.11.010.

[53] T. Wang, W. Li, M. Jia, D. Liu, W. Qin, X. Zhang, Large-eddy simulation of in-cylinder flow in a DISI engine with charge motion control valve: Proper orthogonal decomposition analysis and cyclic variation, Appl. Therm. Eng. 75 (2015) 561-574. https://doi.org/10.1016/j.applthermaleng.2014.10.081.

[54] T.T. Vu, P. Guibert, Proper orthogonal decomposition analysis for cycle-to-cycle variations of engine flow. Effect of a control device in an inlet pipe, Exp. Fluids. 52 (2012) 1519-1532. https://doi.org/10.1007/s00348-012-1268-6. 